\title{
Stationary gas turbines: an exergetic approach to part load operation
}

\author{
Michel Moliere ${ }^{1}$, Jean-Noël Jaubert ${ }^{2,}{ }^{*}$, Romain Privat $^{2}$, and Thierry Schuhler ${ }^{3}$ \\ ${ }^{1}$ Université de Technologie de Belfort-Montbéliard, Laboratoire ICB-LERMPS, rue de Leupe, 90400 Sevenans, France \\ ${ }^{2}$ Université de Lorraine, École Nationale Supérieure des Industries Chimiques, Laboratoire Réactions et Génie des Procédés \\ (UMR CNRS 7274), 1 rue Grandville, 54000 Nancy, France \\ ${ }^{3}$ TOTAL, 2 place Jean Millier, La Défense 6, 92400 Courbevoie, France
}

Received: 5 October 2019 / Accepted: 6 January 2020

\begin{abstract}
As renewables are progressively displacing thermal plants in the power generation scene worldwide, the vocation of stationary Gas Turbines (GT) is deeply evolving. In this irreversible move GT plants are called upon to become cycling units with increasingly variable load profiles. This is dictated by the need to compensate for the fluctuations of renewable energy sources and secure the spinning reserve that is indispensable for the stability of the grids. This new scenario creates a serious challenge for gas turbine designers and operators in terms of investment policy, plant management and equipment lifetime. Indeed, operating a gas turbine at part, variable load requires reducing its firing temperature and possibly its air flow. While part load operation entails efficiency losses with respect to the full load mode, load variations cause maintenance penalties due the premature component ageing tied namely with thermal and low cycle fatigue effects on machine materials. As far as efficiency is concerned, an exergy analysis of a contemporary, air-based Brayton cycle is useful for quantifying and comparing the losses incurred by the various engine components. Such study reveals the high sensitivity of compressor efficiency to load decreases. Among possible counter-measures, heating the air at the compressor intake represents a simple mitigation measure, as it enables reducing the air flow rate while preserving to some extent the efficiency of the compressor and consequently GT efficiency.
\end{abstract}

\section{Introduction}

The gradual displacement of thermal energy by renewables in the power sector impels gas turbine plants to match very variable operation profiles [1] (Fig. 1), as the output of wind and solar plants is intrinsically variable. Gas turbines are thus called upon to operate more and more frequently at part load and must play the role of "peaking units", by performing fast up and down ramping cycles.

There is a wide body of literature devoted to the usefulness of the exergy concept in the field of energy conversion [2-9]. In particular, the interest for exergy-based approaches to thermal power cycles has been growing over the last two decades [10-15], as they provide richer information than simple energy balances. Indeed exergy analyses covering all significant process steps of a system provide interesting feedbacks on several accounts, since:

- They give access to the efficiency gap of each step versus the ideal thermodynamic one and enable pinpointing the most critical step(s).
- One can thus focus the improvement efforts on the most critical process step(s).

- The performance of the system can be monitored in different conditions, including at different operation regimes, which is of obvious interest when the system is an engine.

- One can compare the performances to the ones achieved by similar systems or engines.

Although a sizeable literature already exists about the exergetic evaluation of gas turbine performances operating in simple cycle [16-19], regenerative cycle [20-22], and combined cycle [23-30] or in cogeneration [31-34], most papers focus on the usual operation conditions, which are base or semi-base operation.

To fill this gap, the aim of this paper is to identify the major cause of the loss of efficiency of GT at part load. To that end, we have performed an exergetic study of the performances of a contemporary, single-shaft gas turbine. We have analyzed the exergy balances of the key components, viz. the compressor, the combustion system, the

\footnotetext{
* Corresponding author: jean-noel.jaubert@univ-lorraine.fr
} 


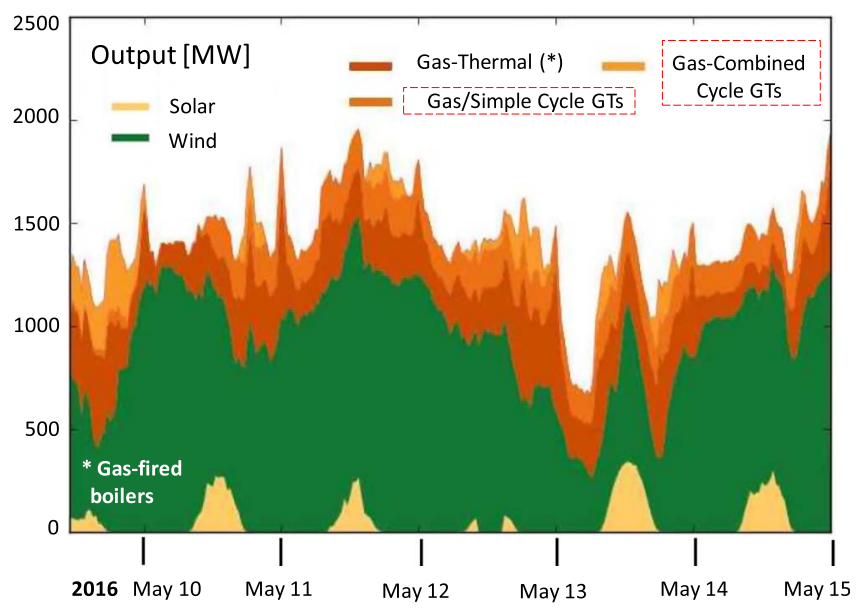

Fig. 1. South Australian grid: typical breakdown of power generation sources [1].

expansion turbine, and the combustion gas exhaust, which constitute the main four elements of the Brayton cycle. Since the matter is about the intrinsic performances of a GT engine, the machine has been considered in simple cycle, i.e. without any exhaust heat recover option. Based on the results of this analysis, the most efficiency-critical subsystem of the cycle has been identified and a suggestion has been brought forward to mitigate this gap and to improve the performance of stationary gas turbines running part load.

\section{Gas turbines in power generation}

Gas turbines dedicated to the production of electricity operate according to the Brayton cycle and deliver its torque and mechanical power to an electric generator $[35,36]$.

Figure 2 shows a typical layout of a single-shaft GT unit operated in simple cycle, i.e. with no heat recovery at their exhaust. This non recuperative configuration is far less used than the combined cycle or cogeneration ones. Nevertheless, Figure 1 shows that simple cycle machines are intensively used as "peaking units" to support the grid. Moreover, they are used in industrial applications requiring strict reliability/availability, e.g. in the oil \& gas Exploration/Production (EP) sector. In this paper, the simple cycle configuration is considered since the goal is to determine how the contributions of the machine components to the exergy balance evolve when the load is changed.

Most of the large machines used in electric applications belong to the group of "heavy-duty" gas turbines (as opposed to aero-derivative's) [36] and the most widespread contemporary models are of the "F-class" type [37]. Their firing temperature (defined as the "TRIT", for "Turbine Rotor Inlet Temperature", or as " $\mathrm{T}_{3}$ ") lies at around $1350{ }^{\circ} \mathrm{C}$ and they develop first-principle efficiencies of around $38 \%$ at ISO ambient conditions (air at $15^{\circ} ; 1$ atm;
$60 \%$ relative humidity). An ideal Carnot operating between a cold source at $15{ }^{\circ} \mathrm{C}$ and a hot source at $1350{ }^{\circ} \mathrm{C}$ would deliver an efficiency of $82 \%$.

Generically, a single-shaft stationary gas turbine rely on three main sub-systems that are its compressor, generally of the axial type, its combustion system and its expansion turbine [38], the working fluid being generally air and the gaseous combustion products.

After the GT has been cranked and accelerated by means of a starting device, it is synchronized to the grid and its shaft rotates at constant speed (e.g., at $3000 \mathrm{rpm}$ for a GT powering a $50 \mathrm{~Hz}$ grid) or at higher speed if it is coupled to the electric generator through a gear box. The operation regime at the nominal rotation speed and zero load (no power yet delivered to the grid) is called "Full Speed-No Load" while "Full Speed-Full Load" or simply "Full Load" refers to the regime at its nominal output rating, for which the performances of the GT are generally optimized. In this paper, the GT load, expressed in \%, is defined as the value of the generated electric power output referred to the nominal one [39].

\section{Exergetic balance of gas turbines}

\subsection{The exergy terms}

The exergy terms of a GT essentially break down in physical and chemical exergy as the potential energy of the working fluid is constant (no change in altitude) and the kinetic one is negligible at system boundaries compared to the gas enthalpy effects [9].

The physical exergy is the theoretical usable work obtainable when the considered system passes from its initial state to its thermomechanical equilibrium state, through reversible physical processes involving only thermal interactions with the environment. The chemical exergy is defined as the theoretical usable work that can be obtained when the system is brought into reaction with the reference substances present in the environment. Its contribution is very important in all combustion processes.

The thermomechanical as well as the chemical equilibrium conditions used for the present exergy analysis correspond to the ISO atmospheric conditions, with the following mole composition of the air: $20.74 \% \mathrm{O}_{2}$, $78.21 \% \mathrm{~N}_{2}$ (argon being aggregated with nitrogen), $0.04 \%$ $\mathrm{CO}_{2}$ and $1.01 \% \mathrm{H}_{2} \mathrm{O}$ (corresponding to $60 \%$ relative humidity).

The fuel considered will be natural gas, assimilated to pure methane and the performance will be investigated at ISO conditions; the composition of the combustion gas at full load will be: $11.77 \% \mathrm{O}_{2}, 75.56 \% \mathrm{~N}_{2}, 3.89 \% \mathrm{CO}_{2}$, $8.77 \% \mathrm{H}_{2} \mathrm{O}$, corresponding to a fuel/air ratio ("FAR") of approximately $0.04(\mathrm{vol} / \mathrm{vol})$. Incidentally, due to the typically low FAR level of GT, the flow of combustion gas $\left(Q_{g}\right)$ is very close to that of air $\left(Q_{a}\right)$.

The schematic of Figure 3 shows the main three subsystems of the gas turbine [40], along with the gas exhaust. The auxiliary equipment items and the electric generator (Fig. 2) are considered as external elements. 


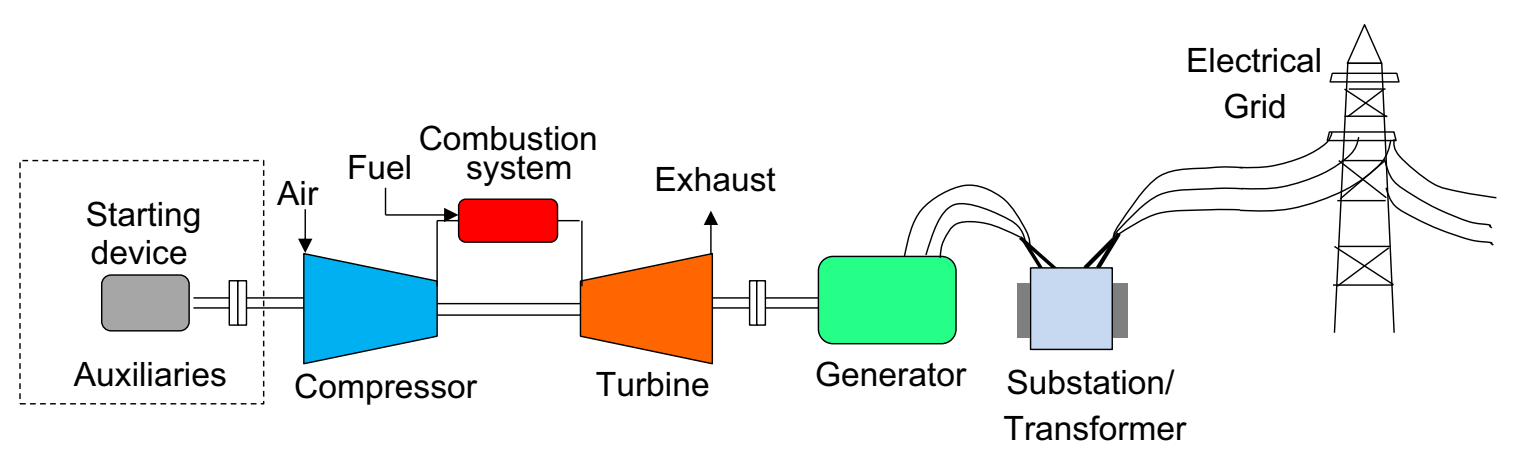

Fig. 2. Simplified sketch of a single-shaft GT operated in simple cycle.

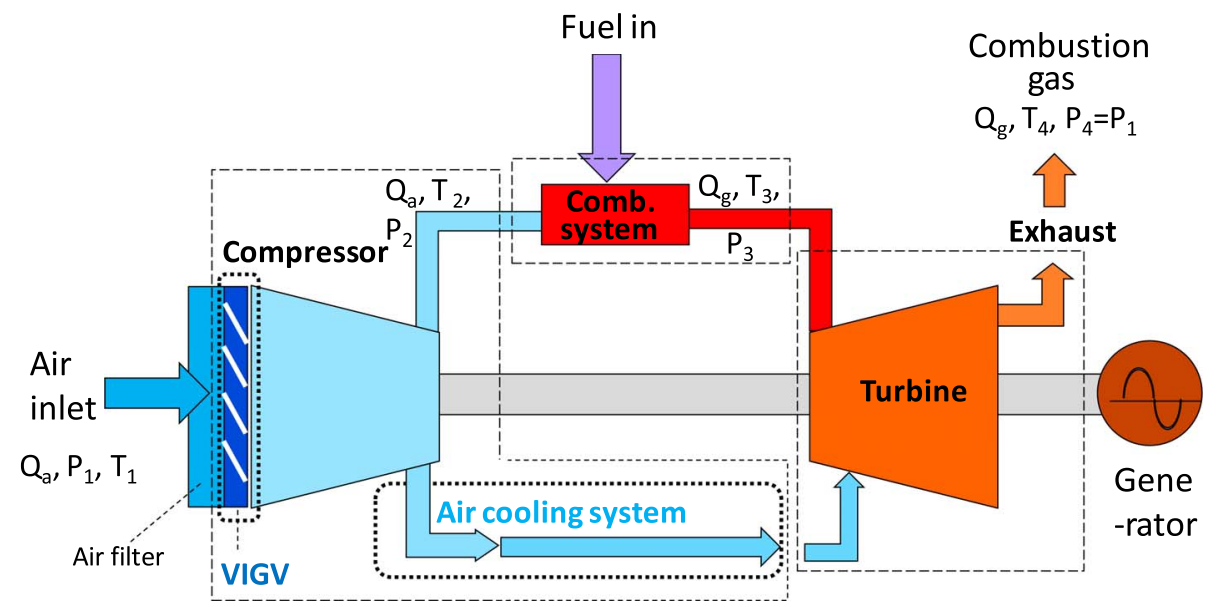

Fig. 3. VIGV and air-cooling systems in a contemporary stationary GT.

Two design features of gas turbines play important roles in the operation and performance of these machines. These are (Fig. 3):

- The "Variable Inlet Guide Vanes" (VIGV) that enable the modulation of the combustion air flow.

- The cooling circuit of the turbine, which is generally performed with air taken from the compressor.

The incidence of both sub-systems on GT performance will be analyzed in the next paragraph.

\subsection{Writing the control exergy balances [41]}

In the analysis below, all exergy/energy terms $\mathrm{Ex}_{j}, W_{j}$ are defined as power data, i.e. as time derivative's of energies. In stationary operation, the balance of exergy ("Ex") of each sub-system " $j$ ", writes:

$$
\begin{gathered}
\operatorname{Ex}_{j}^{\text {in }}=\operatorname{Ex}_{j}^{\text {out }}+W_{j \neq d(\mathrm{PV})}+\operatorname{Ex}_{j}^{\text {destr }}, \\
\text { where }: \operatorname{Ex}_{j}^{\text {destr }}=T_{o} S_{j}^{\text {gener }},
\end{gathered}
$$

$W_{\neq d(\mathrm{PV})}$ represents the mechanical work other than that of the flow work, Ex ${ }^{\text {destr }}$ is the destroyed exergy and $S^{\text {gener }}$ is the corresponding entropy generated.
Figure 4 shows the four sub-systems and the different exergy exchanges between each other on the one hand, and between them and the external elements (generator and ambient air) on another hand.

The exergy losses through machine walls are also neglected because gas turbines are nearly adiabatic systems. The exergy exchanged with the auxiliaries (e.g., lubricant cooling) are not considered as they are minute and marginally altered when the load changes, the aim of the study being to compare the exergy values between full and part load. The same goes for the various frictional losses at the shaft bearings. Similarly, we shall also neglect the change in pressure drop at the air inlet side, including that through the air filters; indeed they are constant at constant air flow, the axial compressor behaving nearly as a volumetric pump irrespective of the GT load. The term "Ex turb" represents the amount of exergy released in the air through the stack of the GT unit. At full load, this term is in fact the most important fraction (over 45\%) of the exergy lost in simple cycle, since we deliberately do not apply any exhaust heat recovery system. Indeed this combustion gas stream is actually very hot (up to $600{ }^{\circ} \mathrm{C}$ ) and moreover contains substantial concentrations of $\mathrm{CO}_{2}$ and $\mathrm{H}_{2} \mathrm{O}$ that are simply released and become irreversibly diluted into the atmosphere. 


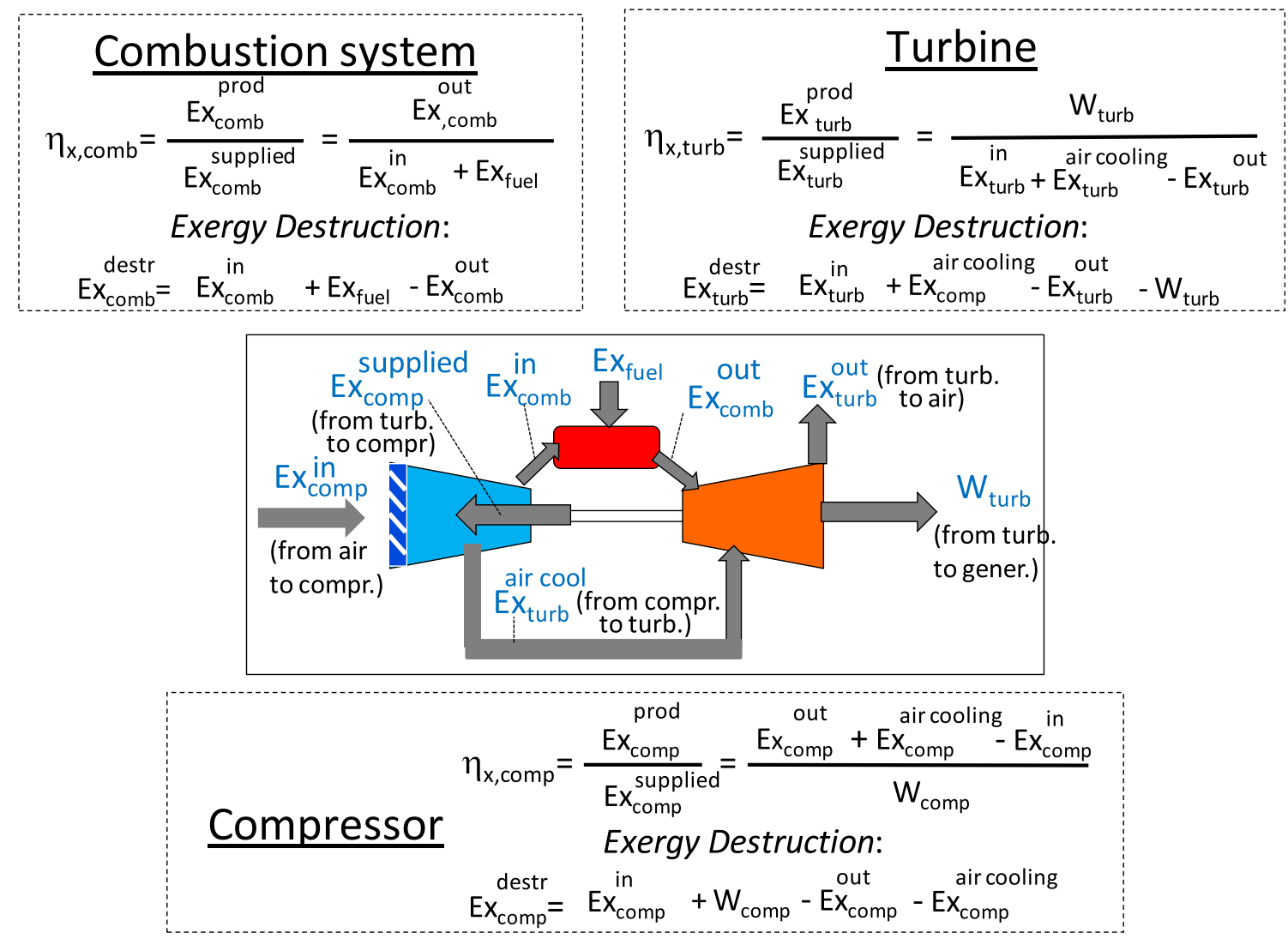

Fig. 4. Expressions of the exergy efficiencies of the different sub-systems.

\section{Importance of the VIGV and turbine cooling systems}

Both the VIGV and the air cooling devices deserve dedicated considerations owing to their important functions and their considerable incidence on GT performances.

\subsection{The VIGV}

VIGV are stationary vanes that are installed at the intake of the compressor, the angle of which can be altered within certain limits by the operator in order to vary the air flow rate [36]. VIGV are sometimes also called "Variable Stator Vanes" (VSV). Some aeroderivative GT have several rows of VSV at different stages in the compressor.

Figure 5 shows an entire compressor cascade assembly (Fig. 5a), with the VIGV row installed ahead of the 1st stator row (Fig. 5b) [42]. A key parameter is the VIGV opening angle " $\alpha$ " (Fig. 5c); one must note that different GT manufacturers of aero- and heavy-duty machines use distinct ways to define $\alpha$ : $90^{\circ}$ may correspond to the axial or radial direction of the vanes and the sign may be moreover inverted.

The modulation of the VIGV whereas the gas turbine ramps up or down, has an important impact on the performances of the compressor and consequently on machine efficiency.
When changing the opening angle $\alpha$ of the VIGV, the air flux entering the compressor gets deviated from its initial main direction: the volume air flow rate becomes then changed as it is the product of the axial component of the air speed by the path cross section. The effect of the VIGV on GT operation is deduced from the expression of the power $\left(P_{\text {turb }}\right)$ delivered by the expansion turbine, which equals the drop of enthalpy across the expansion stages $\left(\mathrm{H}_{3}-\mathrm{H}_{4}\right)$ multiplied by the gas flow $\left(Q_{g}\right.$, which is close to $\left.Q_{a}\right)$ :

$$
\begin{aligned}
P_{\text {turb }} & =\left(H_{3}-H_{4}\right)=Q_{g} \mathrm{Cp}_{g}\left(T_{3}-T_{4}\right) \\
& \approx \boldsymbol{Q}_{\boldsymbol{a}} \mathrm{Cp}_{g}\left(\mathrm{TRIT}-T_{4}\right),
\end{aligned}
$$

$\mathrm{Cp}_{g}$ is the averaged heat capacity of the combustion gas. Therefore:

- To maximize $P_{\text {turb }}$, one shall maximize $Q_{a}$ by opening the VIGV (one also maximizes the (TRIT $-T_{4}$ ) factor, which implies turbine design considerations).

- To decrease $P_{\text {turb }}$, one decreases first TRIT (by burning less fuel), then $Q_{a}$ by closing the VIGV.

By closing the VIGV, one also secures the stability of the combustion process during part load operation, where the FAR is too low to sustain flame stability, with also a risk of excessive emissions of carbon monoxide and unburned hydrocarbons. 

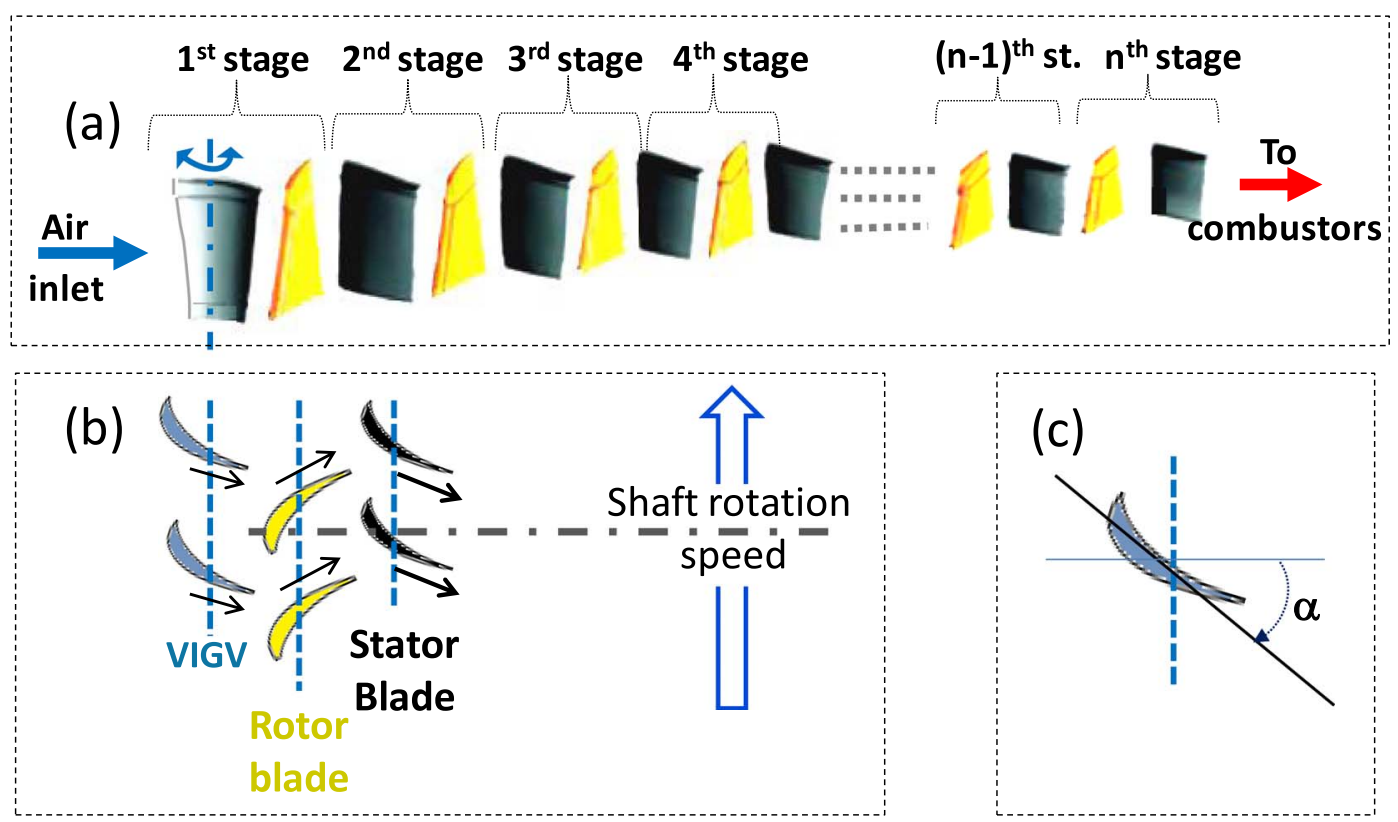

Fig. 5. Compressor VIGV and 1st stage compressor stator blades.

Figure 6 schematizes the relative configuration of the VIGV row and the 1st stage stator compressor blading for different values of $\alpha$ or various air flow rates.

The vectors $W_{\text {rot }}$ and $V_{\text {abs }}$ represent the rotational speed of the 1st stage blade and the absolute velocity of the air leaving the VIGV row, respectively [43, 44]. These vectors are represented in the insert of Figure 6 (upper center). The vector $V_{\text {rel }}$ denotes the velocity of the air relative to the 1st stage blade and equals the vectorial difference between $V_{\text {abs }}$ and $W_{\text {rot. }}$. The vector $V_{\text {ax }}$ that is the projection of $V_{\text {abs }}$ (or $V_{\text {rel }}$ ) on the GT axis, is simply the "axial velocity" of the air; it is kept constant by design along the blade cascade by decreasing the compressor annulus section " $S_{\text {an }}$ " and the blade span (Fig. 5a), as the pressure increases from upstream towards downstream. The volume air flow rate $Q_{a}$ can be calculated at any stage by multiplying $V_{\text {ax }}$ by $S_{\text {an }}$.

"Case 0" corresponds to the optimum value of the VIGV angle $\left(\alpha_{\text {opt }}\right)$. Here the relative velocity $V_{\text {rel }}$ of the air is parallel to chord $(C)$ of the 1st stage rotating blades, which has several beneficial effects:

- The aerodynamic turbulences during the passage of the air through the throat of the rotor blading is minimized, resulting in a minimum loss of mechanical exergy.

- The relative velocity $V_{\text {rel }}$ is limited in intensity ("diffusion effect").

If one progressively closes the VIGV with respect to the case 0 (case 1 ), then $V_{\text {abs }}$ (or more precisely its radial projection $V_{\text {rad }}$ ) becomes oriented opposite to $V_{\text {rot }}$ and the direction of the resulting $V_{\text {rel }}$ deviates from that of the chord $(C)$ by a negative angle $\left(\delta_{1}<0\right)$ : this tends to cause separation of the Boundary Layer (BL) and turbulences along the suction side of the rotating blades that gets "stalled" [45]. Stall degrades flow aerodynamics, impairs the compression process and entails moreover mechanical stress and vibrations of the blade. It can propagate to the next stages and result in extreme cases in compressor surge. An alternative occurrence of boundary layer separation on the suction side is in case of strong air flow restriction (case 2: $V_{\text {ax }}$ gets decreased) at constant VIGV opening.

To the contrary, if one opens more the VIGV as compared with case 0 (case 3 ), while keeping the air flow constant $\left(V_{\mathrm{ax}}=\mathrm{cst}\right)$, then $V_{\text {rel }}$ forms a positive angle with the chord $\left(\delta_{3}>0\right)$, which tends to cause separation of the boundary layer along the pressure side of the 1st stage blade. A boundary layer separation occurs also on the pressure side in case of excessive increase of air flow rate at constant VIGV opening (case 4).

Due to the energy intensity of gas compression, every boundary layer separation entails a higher loss of exergy, a degradation of compressor efficiency and consequently a loss in GT efficiency [44]. In summary the ideal operation of the compressor at changing load would require the most suitable adjustment of the IGV angle at each operation point of the compressor, i.e. in function of its air flow, to avoid efficiency penalties in the compression process.

The role of the VIGV opening in the variation of exergy losses at changing load will be set out in the next section.

\subsection{The air cooling system of the turbine}

Turbine air cooling is another important sub-system of modern gas turbines (Fig. 7) [46]. To maximize the firing temperature without damaging the hot turbine parts, the first stages of stationary blades (or "partition vanes") and rotating blades (or "buckets") are cooled (Fig. 3) [47]. This cooling is achieved by extracting a flow of air from the last compressor stages (at a typical temperature between $350{ }^{\circ} \mathrm{C}$ and $450{ }^{\circ} \mathrm{C}$ ) and passing it through cooling holes that are 
Case 1: $\alpha_{1}<\alpha_{\text {opt }}, Q_{a}=$ Cst Negative deviation angle: $B \mathrm{~L}$ separates on suction side
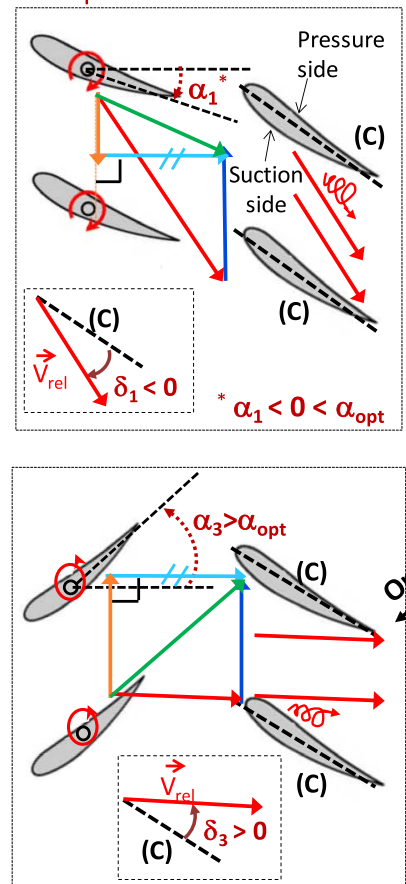

Case 3: $\alpha_{3}>\alpha_{\text {opt }}, Q_{a}=$ Cst Positive deviation angle: $\mathrm{BL}$ separates on pressure side

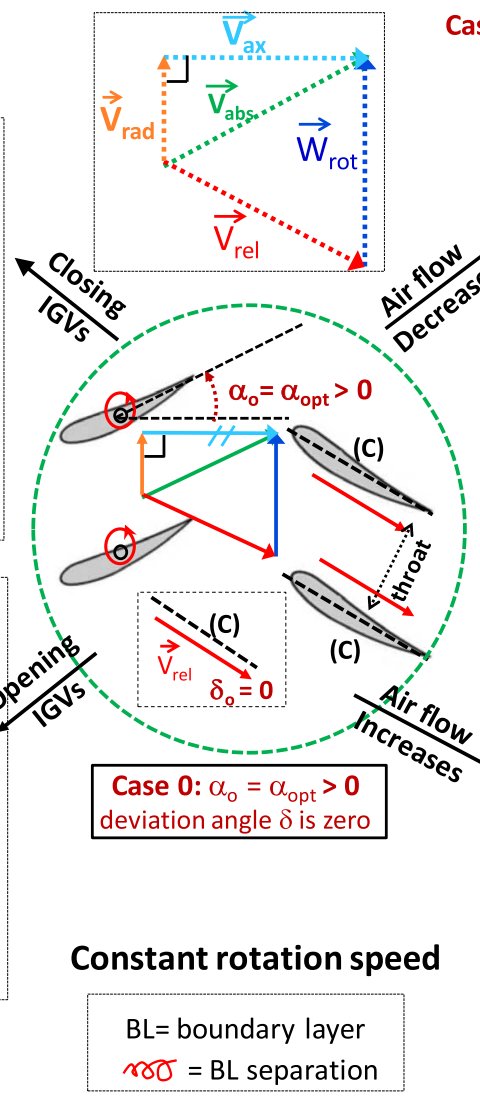

Case 2: $\alpha_{2}=C s t=\alpha_{\text {opt }}$, decreased $Q_{a}$ Negative deviation angle :

$B L$ separates on pressure side
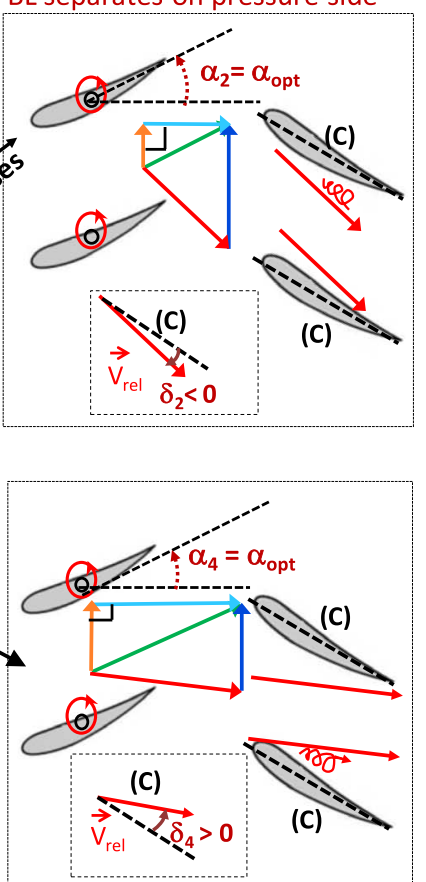

Case 4: $\alpha_{4}=\alpha_{\text {opt }}$, increased $Q_{a}$ Positive deviation angle : $\mathrm{BL}$ separates on pressure side

Fig. 6. Effect of IGV opening angle $(\alpha)$ on the flow dynamics in the compressor: case 0: design case; cases 1 \& 2 : by closing VIGV or reducing air flow at $\operatorname{cst} \alpha, V_{\text {rel }}$ deviates towards pressure side; cases $3 \mathscr{E} 4$ : by opening VIGV or increasing air flow at cst $\alpha, V_{\text {rel }}$ deviates towards suction side.

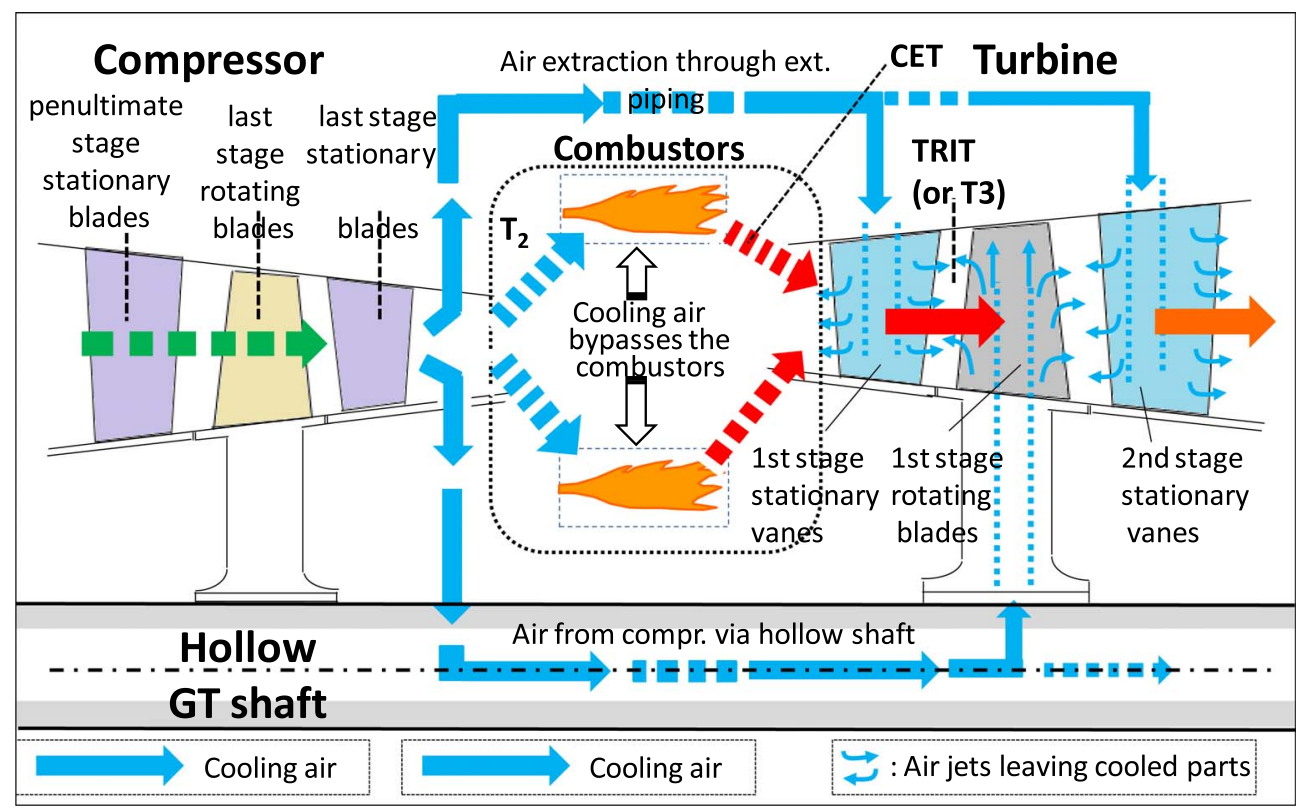

Fig. 7. Turbine air cooling system (axial section of compressor and turbine). 
drilled inside the hottest parts of the expansion turbine. Generally the first and second stages of the turbine are cooled in this way as they operate in the hottest environment, with combustion gases typically at $1100-1500{ }^{\circ} \mathrm{C}$ in the 1st stage.

In this exergy approach, the air cooling system is dealt with as a subset of the compressor (Fig. 3).

The routing of the air cooling from the compressor to the turbine is done through two paths (Fig. 7): some outboard air streams (through external pipes) cool the stationary blades while some inboard air streams (through the hollow GT shaft) cool the rotating blades. When they leave the parts after having cooled them, the jets of cooling air are injected in and mixed with much hotter and highly turbulent combustion gas, which causes substantial creation of entropy and a correlative destruction of thermal exergy. In addition, the efficiency of the mechanical work performed by the cooling air inside the turbine is very poor since these air jets do not properly tackle the rotating parts, a fraction being moreover ejected downstream of the latter.

The implementation of internal air cooling or - more rarely - of external steam cooling [48], is indispensable. Indeed it enables the very high firing temperature (TRIT) that are developed in modern gas turbines to enhance efficiency and it protect the materials of the hot path parts against any thermal damage or abnormal ageing by oxidation, creeping or thermal fatigue.

These materials are generally nickel-based "superalloys" that are additionally coated with thermally insulating ceramic coatings ("Thermal Barrier Coatings" [TBCs]), such as Yttria-Stabilized Zirconia ("YSZ"). The combination of TBC and internal air cooling causes a reduction by $100-200{ }^{\circ} \mathrm{C}$ of the skin temperature of the vanes and blades [49]. It should be noted that nickel has a melting point of $1455^{\circ} \mathrm{C}$ and that the TRIT may be close to or even exceed this value in current GT designs.
Figure 8 shows a TBC-coated rotating blade and an internal cooling channel having a serpentine shape: the cooling air is discharged through a series of tip and side holes.

Depending on the degree of design sophistication of the turbine hot gas path, the first three stages - and sometimes the fourth one - are cooled in this way. It is noteworthy that, since the 1st stage stator blades are cooled, there is a difference between the Combustor Exit Temperature ("CET" assimilated to the cycle temperature $T_{3}$ ) and the Turbine Rotor Inlet Temperature (TRIT), which is lower (Fig. 7). One can employ TBC materials that are still more refractory than YSZ and have still lower thermal conductivities, such as yttrium garnets or rare earth zirconates, but such expensive materials are reserved to aerospace applications for the time being [50].

Only technologies involving ceramic materials [51, 52] are capable of addressing such hot operation environment without or with much reduced internal cooling. These novel materials are either monolithic ceramics, such as silicon carbide or nitride $\left(\mathrm{SiC}, \mathrm{Si}_{3} \mathrm{~N}_{4}\right)$ or Ceramic Matrix Composites (CMCs) made of a ceramic or vitreous matrix ( $\mathrm{SiC}, \mathrm{Al}_{2} \mathrm{O}_{3}$, $\mathrm{Si}_{3} \mathrm{~N}_{4}$ ) reinforced by ceramic fibers, whiskers or particles. They are more than twice lighter than superalloys and boast very high hardness and strength properties. However their main drawback is their mechanical brittleness and they are also subject to "recession", a process in which silicon $(\mathrm{Si})$ is oxidized by $\mathrm{H}_{2} \mathrm{O}$ contained in the combustion gas with the formation of silica $\left(\mathrm{SiO}_{2}\right)$ and volatile silicic acid $\left(\mathrm{Si}(\mathrm{OH})_{4}\right)[53,54]$. Therefore, they need Environmental Barrier Coatings ("EBC"), most often based on costly rare-earth silicates [55].

Both the VIGV and the air-cooling systems are indispensable to secure the trouble-free and efficient operation of modern gas turbines over their entire operation range, from startup to full or peak load.

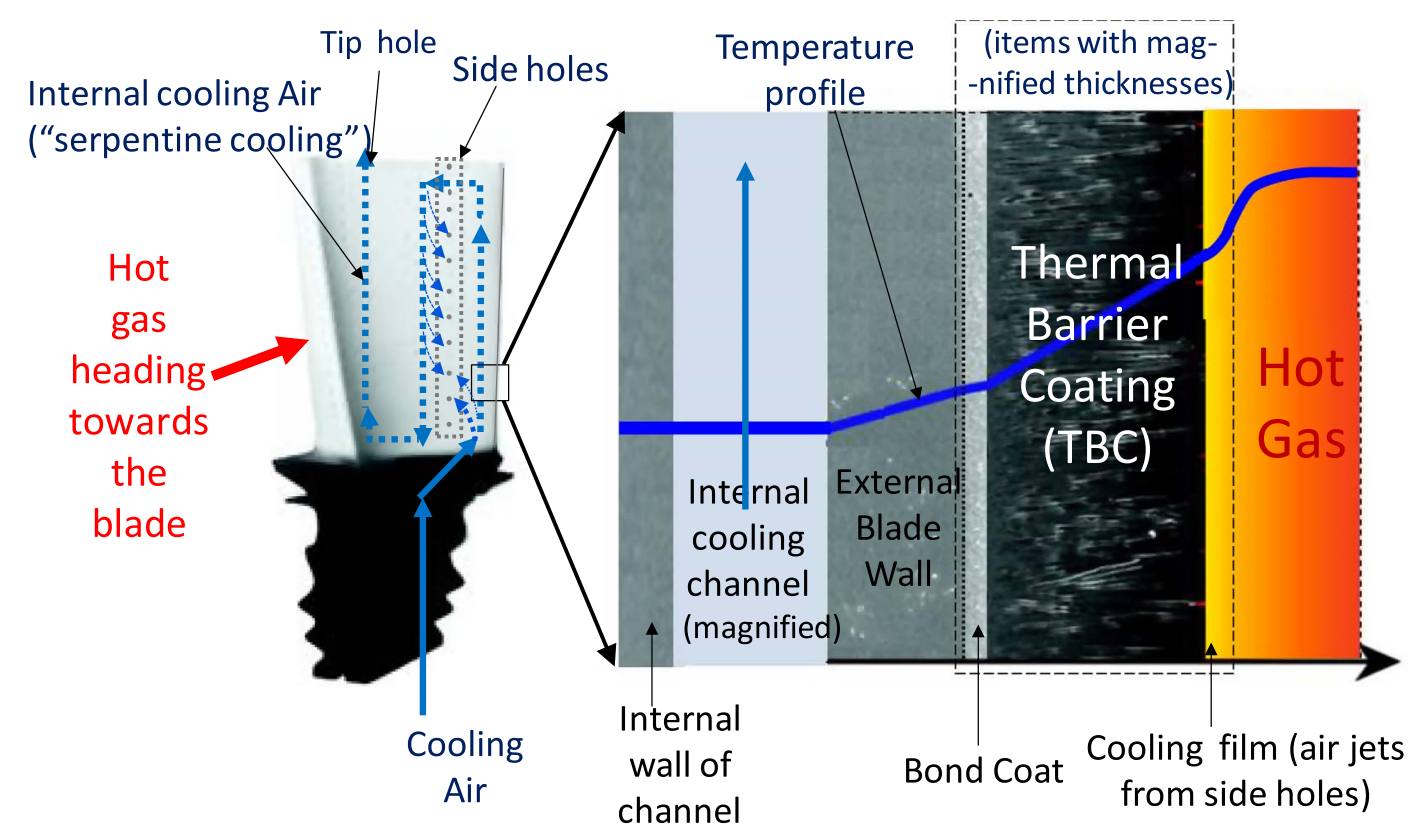

Fig. 8. Cross section of a typical TBC-coated blade with one of its cooling channel [49]. 


\subsection{Other GT subsystems}

Apart from these two devices, some others have been introduced later, such as Dry Low NOx ("DLN") or Dry Low Emission ("DLE") combustors [56, 57]. DLN systems are designed to perform combustion in "premix mode" by intimately mixing air and fuel upstream of the flames; they are necessary in contemporary gas turbines to cope with the increasingly exacting emission regulations that apply to the oxides of nitrogen (NOx) generated in the hot GT flames. DLN combustors do not degrade efficiency. "Inlet Bleed Heating" ("IBH") is often used in association with DLN to stabilize the premix combustion mode at low loads [58]. It consists in recirculating some compressed air back to the compressor intake in order to increase $T_{1}$ and consequently decrease $Q_{a}$ at constant load, whereby increasing $T_{3}$. When it is used, IBH tends to further degrade exergy but its consideration would go beyond the scope of this paper.

\section{Result of exergy calculations}

Figure 9 brings together the results of the exergy analysis obtained at full load and at four part loads. One clearly sees that the second-principle efficiency gets substantially reduced when the load decreases, accounting for the worsening of energy conversion irreversibilities. One may note that the efficiency drops to null at "FSNL", since no power is produced at this very particular, transient regime at which the major part of the energy of the fuel is spent to sustain the rotation of the shaft (by overcoming the aerodynamic drags in the turbine/compressor) and the rest is wasted as heat at the GT exhaust.

It must be stressed that the strong drops of efficiency observed at part loads are largely due to the fact that the calculations are made in simple cycle configuration, in accordance with the goal of this study. Should the same machine be used not in simple cycle but in combined cycle with e.g. a three-pressure steam cycle, then the exergy performance would reach $60-61 \%$ at full load and remain rather stable with about $53 \%$ at $40 \%$ load. If operated in cogeneration application, this class of gas turbine would deliver overall energy (power + heat) recovery figures in the range of 80 $90 \%$ for GT load varying between $30 \%$ and $100 \%$.

Figure 10 compares the break-down of the exergy losses at $100 \%$ load and $25 \%$ load.

The major effects can be summarized as follows:

- The fraction of exergy lost at the GT exhaust drops from $47 \%$ at full load to $39 \%$ at low load because the exhaust temperature $\left(T_{4}\right)$ gets lowered.

- The fraction of exergy lost in the combustors is high but is only slightly affected by load changes.

- The fraction of exergy lost in turbine is virtually unchanged (around 7\%).

- In contrast, the fraction of exergy lost in the compressor is multiplied by 3 , passing from $3 \%$ to $9 \%$.

As an outstanding outcome of this analysis, one observes that, while the compressor incurs a strong degradation of

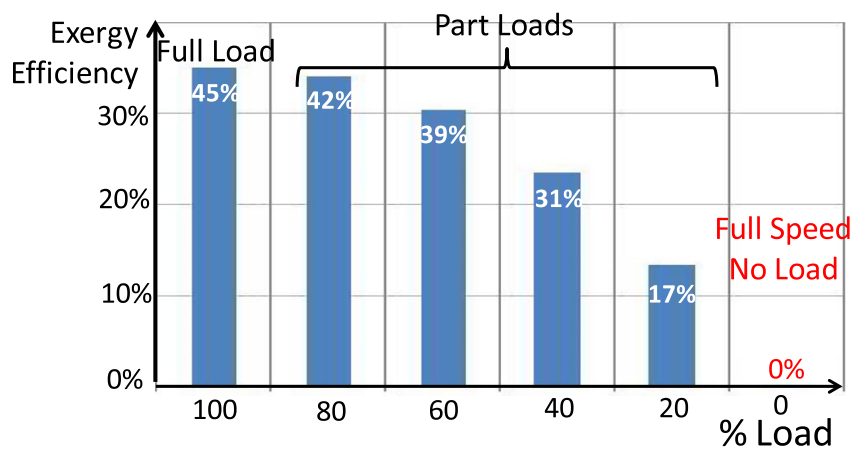

Fig. 9. Exergy efficiency at different loads.

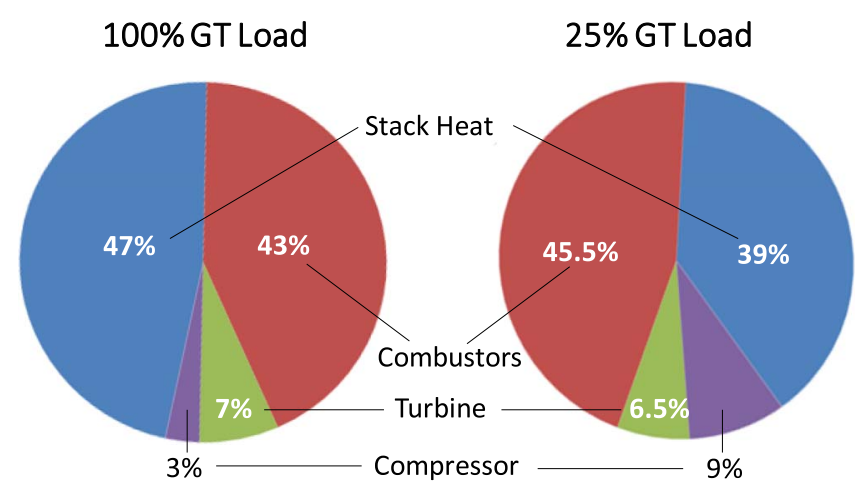

Fig. 10. Compared break-downs of exergy losses at $100 \%$ and $25 \%$ load.

efficiency at part load, on the contrary, the turbine proves to be relatively insensitive to the changes in flow patterns (pressure, temperature, and velocity) that are associated with load changes.

This difference in behavior can be explained by the fact that increasing the pressure of a compressible fluid by a ratio higher than say 1.5 requires a multistage compressor to prevent surge issues (in an F-class GT, the Pressure Ratio "[PR]" is in the order of 15). Now, to ensure "smooth", efficient aerodynamics in a multistage compressor, the relative velocity vector of the air flow at the exit of each row " $n$ " must be as parallel as possible to the chord $(C)$ of the row " $n+1$ ", as illustrated in Figure 6 ("case 0" circled in green). Any deviation from this ideal rule, i.e. a substantially positive or negative incidence angle $\delta$, will negatively reflect on the effectiveness of the exchange of momentum between the air stream and the blades: this is likely to create eddies and secondary flows, resulting in possible boundary layer separations that can be amplified by a cumulative effect from one stage to the next one. On the contrary, expansion turbines have much less stages than compressors (e.g., 3 vs. 17) and are less sensitive to such "cascade effect".

To get a closer understanding of the importance of the VIGV opening, it is helpful to refer to a generic compressor operation map, which is schematically represented in Figure 11.

A compressor map relates the pressure ratio to the "corrected air flow rate" normalized to the inlet air temperature 


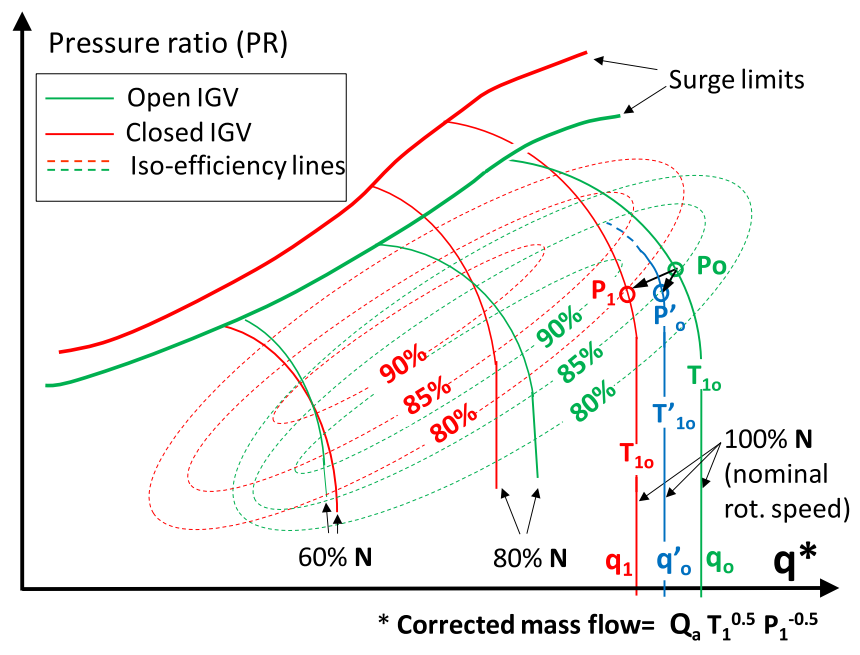

Fig. 11. Compressor map: effects of closing the VIGV angle and air heating.

and pressure [59-61]. The corrected air flow rate " $q$ ", expressed in mass, is defined as $q=Q_{a} T_{1}{ }^{0.5} P_{1}^{-0.5}$, where $Q_{a}$ is the air flow rate. In Figure 11 the green and red lines refer to the operation with open and closed VIGV respectively. The bold solid lines are the surge limits. The thin solid lines represent the lines of iso-rotation speeds (" $N ")$ of the shaft: since the GT is a single-shaft one, only the nominal rotation speed is to be considered as soon as the GT has been synchronized to the grid. The dotted closed curves are the iso-efficiency lines: they are schematically drawn as an array of ellipses. This array of iso-efficiency curves becomes shifted to the left top side of the figure when the VIGV get closed [62].

Let us visualize the effect of closing the VIGV by starting from the initial point " $P$ " for which the air temperature is $T_{1 o}$, the air flow is $Q_{a o}$ and the polytropic efficiency is e.g. 85\%; the corrected flow $q_{o}$ equals $Q_{a o} T_{10}{ }^{0.5} P_{1}^{-0.5}$. As the rotation speed remains constant, the closing of VIGV causes a reduction in the corrected air flow, which becomes $q_{1}<q_{\mathrm{o}}$. This reduction of air flow causes a slight decrease of the pressure ratio $\mathrm{PR}$ as the counter-pressure in the turbine is slightly reduced. Therefore, during a partial closing of the VIGV, the initial operation point " $P$ " moves to a position like " $P_{1}$ " that lies on an ellipse of lower efficiency. As shown by this schematic diagram, the drop in polytropic efficiency can amount several percents.

In summary, the present exergy evaluation shows the high sensitiveness of the compressor efficiency to load drops, an effect which is correlated with the changes in its operation conditions and particularly in the VIGV opening.

\section{Discussion: possible improvement of part load efficiency}

There are different possibilities for enhancing GT efficiency at constant part load. Major alterations of the cycle are theoretically possible but most often impractical as they increase equipment complexity and add considerable extracosts. They may also affect machine reliability/availability and there is often a lack of time to implement such hardware modifications or insufficient space to install them, in the case of retrofits.

Increasing simply the firing temperature without decreasing $Q_{a}$ would not bring the solution as it would also increase the power output, which contradicts the objective.

The only practicable option available to increase efficiency at constant load without increasing cycle complexity seems to be by decreasing the air flow rate $Q_{a}$.

When doing so and provided the gas turbine is operated in the load control mode, its control loop will automatically and straightaway increase the firing temperature TRIT to maintain the power output level at the specified level. Now, the traditional means to decrease $Q_{a}$ consists in closing the VIGV but the foregoing analysis shows that the compressor efficiency results negatively affected.

An alternative measure is to simply heat the inlet air, which also causes a decrease in air mass flow rate $Q_{a}$ and therefore dispenses from changing the VIGV opening angle [63]. The control loop will again compensate this decrease in air flow by increasing of TRIT to keep the power output constant, but this time there will be no degradation of compressor efficiency.

To illustrate this strategy, using again the compressor map of Figure 11, one can materialize the effect of inlet air heating, starting also from the operation point $P_{o}$. Let us heat the compressor inlet air from $T_{1 o}$ to $T_{1 o}^{\prime}$ (e.g., from $293 \mathrm{~K}$ to $353 \mathrm{~K}$ ). Since an axial compressor behaves nearly as a volumetric pump, the air mass flow rate is proportional to the air density i.e. inversely proportional to its temperature. Therefore the corrected air flow becomes:

$$
\begin{aligned}
q_{o}^{\prime} & =Q_{a o}^{\prime} T_{1 o}^{\prime 0.5} P_{1}^{-0.5}=Q_{a o}\left(T_{1 o} / T_{1 o}^{\prime}\right) T_{1 o}^{\prime}{ }^{0.5} P_{1}^{-0.5} \\
& =q_{o}\left(T_{1 o} / T_{1 o}^{\prime}\right)^{0.5} .
\end{aligned}
$$

Therefore it decreases slightly by the factor $\left(T_{1 o} / T_{10}^{\prime}\right)^{0.5}$. The PR is also little affected: the operation point passes from $P_{o}$ to the position $P_{o}^{\prime}$, which does not depart much from the initial iso-efficiency line.

Such heating can be made using hot water or steam prepared from a very simple Waste Heat Recovery Unit (WHRU) installed at GT exhaust. One can also use the heat exchanger of the anti-icing system, provided the gas turbine is equipped with such system.

\section{Conclusion}

This paper has set out an exergy analysis of a contemporary stationary gas turbine running at variable load within a power generation application. The simple cycle configuration has been used to identify the contributions of the different components of the gas turbine engine, namely the compressor, the combustion system, the turbine and the gas exhaust. This analysis shows that the compressor tends to be a "weak element", in terms of efficiency retention, when the machine is operated at low load. 
To interpret this effect, it has been necessary to consider the setting of the VIGV which controls the cycle air flow as well as the air-cooling process of the hot gas parts, as both impact the energy performances of modern gas turbines. The strategies for improving the efficiency of simple cycle gas turbines running part load should focus on reducing the air flow while keeping optimum the aerodynamics along the compressor path, which implies an optimized management of the VIGV opening in function of the GT load. A light and efficient option could consist in heating the inlet air, which causes a reduction of GT load without significantly degrading the efficiency of the compressor. This can be done by recovering some of the waste heat which is available in great amount at the GT exhaust.

Interestingly, the rather complex interaction of the VIGV system with the other engine functions illustrates the trend for increased complexity faced in the design of contemporary industrial engines, such as diesel engines, aircrafts, automotive vehicles, etc. In addition energy conversion efficiency is not the sole requirement as these products must cope with an increasingly complex set of operational constraint in relation with safety, reliability, efficiency, operation flexibility, emission compliance, while keeping costs to a reasonable level.

Finally, one must add that the simple cycle scenario that has been selected for the purpose of this exergy analysis should not be taken as a paradigm for the world fleet of stationary gas turbines units, which are most often operated in combined cycle or in cogeneration and develop much better efficiency at part load.

\section{References}

1 Parkinson G. Wind and solar become new base load power for South Australia, Clean Energy News and Analysis. https:// reneweconomy.com.au/wind-and-solar-become-new-baseload-power-for-south-australia-99364/, 2016.

2 Tsatsaronis G., Pisa J. (1994) Exergo-economic evaluation and optimization of energy systems - application to the CGAM problem, Energy 19, 3, 287-321.

3 Moran M.J., Sciubba E. (1994) Exergy analysis: Principles and practice, J. Eng. Gas Turbines Power 116, 2, 285-290.

4 Bejan A., Moran M.J. (1996) Thermal design and optimization, John Wiley \& Sons, NJ, USA.

5 Rosen M.A. (2004) Exergy analysis of energy systems, in: Cleveland C.J. (ed), Encyclopedia of energy, Vol. 2, Elsevier, Amsterdam; Boston, pp. 607-621.

6 Woudstra N., Woudstra T., Pirone A., van der Stelt T. (2010) Thermodynamic evaluation of combined cycle plants, Energy Convers. Manage. 51, 5, 1099-1110.

7 Moran M.J., Shapiro H.N., Boettner D.D., Bailey M.B. (2010) Fundamentals of engineering thermodynamics, John Wiley \& Sons, Hoboken, NJ, USA.

8 Dincer I., Rosen M.A. (2012) Exergy: Energy, environment and sustainable development, Elsevier, Amsterdam, The Netherlands.

9 Gilbert A., Mesmer B., Watson M.D. (2016) Uses of exergy in systems engineering, in: Proceedings of the 2016 Conference on Systems Engineering Research, Mar 22-24, Huntsville, AL.
10 Kotas T.J. (1985) The exergy method of thermal plant analysis, Butterworth-Heinemann, Oxford, UK.

11 Chin W.W., El-Masri M.A. (1986) Exergy analysis of combined cycles - part 2: Analysis and optimization of two-pressure steam bottoming cycles, in: Presented at the Jt. ASME/IEEE Power Generation Conference, October 19-23, Portland, OR. Paper no. 86-JPGC-GT-10.

12 Kaushik S.C., Siva Reddy V., Tyagi S.K. (2011) Energy and exergy analyses of thermal power plants: A review, Renew. Sust. Energ. Rev. 15, 4, 1857-1872.

13 Regulagadda P., Dincer I., Naterer G.F. (2010) Exergy analysis of a thermal power plant with measured boiler and turbine losses, Appl. Therm. Eng. 30, 8-9, 970-976.

14 Hou D., Shao S., Zhang Y., Liu S.L., Chen Y., Zhang S.S. (2012) Exergy analysis of a thermal power plant using a modeling approach, Clean Technol. Environ. Policy 14, 5, 805-813.

15 Horlock J.H., Young J.B., Manfrida G. (2000) Exergy analysis of modern fossil-fuel power plant, ASME J. Eng. Gas Turbines Power 122, 1-7.

16 Marija Ž., Galovi A., Virag Z. (2014) Detailed analysis of the effect of the turbine and compressor efficiency on thermal and exergy efficiency of a Brayton cycle, Therm. Sci. 18, 3, 843-852.

17 Pattanayak L. (2015) Thermodynamic modeling and exergy analysis of gas turbine cycle for different boundary conditions, Int. J. Power Electron. Drive Syst. 6, 2, 205-215.

18 Marija Ž., Galovic A., Avsec J., Holik M. (2016) Exergy analysis of a Brayton cycle with variable physical properties and variable composition of working substance, Tehnički Vjesnik 23, 3, 801-808.

19 Betelmal E.H., Farhat S.A. (2018) Energy and exergy analysis of a simple gas turbine cycle with wet compression, Mech. Eng. Res. 8, 1, 30-40.

20 Kousuke N., Shinich K. (2005) Regenerative steam-injection gas-turbine systems, Appl. Energy 81, 3, 231-246.

21 Naserian M.M., Farahat S., Sarhaddi F. (2017) New exergy analysis of a regenerative closed Brayton cycle, Energy Convers. Manage. 134, 116-124.

22 Khan M.N., Tlili I. (2019) New approach for enhancing the performance of gas turbine cycle: A comparative study, Results Eng. 2, 100008, 1-10.

23 El-Masr M.A. (1987) Exergy analysis of combined cycles: Part 1 - air-cooled brayton-cycle gas turbines, J. Eng. Gas Turbines Power 109, 2, 228-236.

24 Facchini B., Fiaschi D., Manfrida G. (2000) Exergy analysis of combined cycles using latest generation gas turbines, $J$. Eng. Gas Turbines Power 122, 233-238.

25 Shin J.Y., Jeon Y.J., Maeng D.J., Kim J.S., Ro S.T. (2002) Analysis of the dynamic characteristics of a combined-cycle power plant, Energy 27, 12, 1085-1098.

26 Deng-Chern S., Chia-Chin C. (2004) Engineering and exergy analyses for combustion gas turbine based power generation system, Energy 29, 8, 1183-1205.

27 Polyzakis A.L., Koroneos C., Xydis G. (2008) Optimum gas turbine cycle for combined cycle power plant, Energy Convers. Manage. 49, 4, 551-563.

28 Petrakopoulou F., Tsatsaronis G., Morosuk T., Carassai A. (2012) Conventional and advanced exergetic analyses applied to a combined cycle power plant, Energy 41, 146-152.

29 Metha N., Mehta N.S., Panchal C.P. (2014) Exergy analysis of gas turbine power plant, Int. J. Sci. Eng. Res. 5, 2, $712-716$. 
30 Mishra R.S., Singh A. (2017) Thermodynamic (EnergyExergy) analysis of combined cycle gas turbine power plant (CCGT) for improving its thermal performances, Int. J. Res. Eng. Innov. 1, 4, 9-24.

31 Feidt M., Costea M. (2012) Energy and exergy analysis and optimization of combined heat and power systems - comparison of various systems, Energies 5, 3701-3722.

32 Dincer I., Rosen M.A. (2007) Energy analysis of cogeneration and district energy systems, in: Exergy - energy, environment and sustainable development, Chap. 12, Elsevier, Amsterdam, The Netherlands, pp. 257-276.

33 Kaviri A.G., Jafar M.N.M., Tholudin M.L., Avval H.B. (2011) Exergy analysis of a cogeneration heat and power (CHP) system (first and second law analysis), in: 2011 IEEE Conference on Clean Energy and Technology (CET), 27-29 June, Kuala Lumpur, Malaysia.

34 Balli O., Aras H., Hepbasli A. (2008) Exergo-economic analysis of a combined heat and power (CHP) system, Int. J. Energy Res. 32, 273-289.

35 Walsh P.P., Fletcher P. (2004) Gas turbine performance, 2nd edn., Blackwell Science, Hoboken, NJ.

36 Soares C. (2015) Gas turbines: A handbook of air, land and sea applications, Elsevier, Amsterdam, The Netherlands.

37 EPRI Report No 1025357. (2012) F-class gas turbine technology summary: Design features, reliability statistics, and durability issues, Palo Alto, CA.

38 Gas Turbine Power Plants, Electropaedia. https://www. mpoweruk.com/gas turbines.htm.

39 Prade B. (2013) Gas turbine operation and combustion performance issues, in: Modern gas turbine systems, high efficiency, low emission, fuel flexible power generation, Chap. 10, Woodhead Publishing Series in Energy, Oxford, pp. 383422 .

40 Brandt D.E., Wesorick R.R. (1994) Gas turbine design philosophy, GE Industrial \& Power Systems, Schenectady, NY. GER-3434D. https://www.ge.com/content/dam/gepower-pgdp/ global/en_US/documents/technical/ger/ger-3434d-ge-gasturbine-design-philosophy.pdf.

41 Frangopoulos C.A. (ed) (2009) Exergy, energy system analysis and optimization - Volume I, EOLSS Pub, Oxford, UK.

42 Langston L.S. Gas turbine compressors: Understanding stall, surge, Combined Cycle J. 50, http://www.ccj-online.com/ combined-cycle-journal-number-50/gas-turbine-compressors-understanding-stall-surge/, 2017.

43 Saravanamuttoo H., Cohen H., Rogers G.F.C. (2013) Gas turbine theory, 5th edn., Pearson, London, UK.

44 Dixon S.L., Hall C.A. (2014) Fluid mechanics and thermodynamics of turbomachinery, 7th edn., ButterworthHeinemann/Elsevier, Oxford, UK.

45 Marty J., Castillon L., Boniface J.-C., Burguburu S., Godard A. (2013) Numerical and experimental investigations of flow control in axial compressors, Aerosp. Lab J. 6, 1-13.

46 Bunker R.S. (2008) Innovative gas turbine cooling techniques, WIT Trans. State Art Sci. Eng., 42, 199-229. WIT Press

47 Han J.C., Dutta S., Ekkad S. (2000) Gas turbine heat transfer and cooling technology, Taylor \& Francis, Abingdon, UK.
48 Carnevale E.A., Facchini B., Ferrara G. (1998) A rotor blade cooling improvement for heavy duty gas turbine using steam and mixed steam/air cooling, in: International Gas Turbine and Aeroengine Congress and Exposition, June 2-5, Stockholm, TX. Paper 98-GT-275.

49 Clarke D.R., Oechsner M., Padture N. (2012) Thermalbarrier coatings for more efficient gas-turbine engines, MRS Bull. 37, 891-898.

50 Gell M., Wang J., Kumar R., Roth J., Jiang C., Jordan E.H. (2018) Higher temperature thermal barrier coatings with the combined use of yttrium aluminum garnet and the solution precursor plasma spray process, J. Therm. Spray Technol. 27, 4, 543-555.

51 Heinrich J.G., Aldinger F. (ed) (2001) Ceramic materials and components for engines, Wiley VCH, Weinheim, Germany.

52 Bright E., Burleson R., Dynan S.A., Collins W.T. (1995) NT1 64 silicon nitride gas turbine engine turbine blade manufacturing development, in: International Gas Turbine and Aeroengine Congress and Exposition, June 5-8, Houston, TX. Paper 95-GT-74.

53 Shunkichi U., Tatsuki O., Hua-Tay L. (2007) Recession behavior of a silicon nitride with multi-layered environmental barrier coating system, Ceram. Int. 33, 5, 859-862.

54 Schenk B., Strangman T., Opila E.J., Robinson R.C., Fox D.S., Klemm H., Taut C., More K.L., Torterelli P. (2001) Oxidation behavior of prospective silicon nitride materials for advanced microturbine applications, in: Proceedings of the 46th ASME Turbo Expo Land, Sea, and Air, June 4-7, NO, USA. Paper 2001-GT-0459.

55 Hai-Doo K., Hua-Tay L., Hoffmann M.J. (2005) Advanced Si-based ceramics and composites, Key Eng. Mater. 287, 10-15.

56 Davis L.B. (1996) Dry low NOx combustion systems for GE heavy duty gas turbines, in: International Gas Turbine and Aeroengine Congress $\&$ Exhibition, June 10-13, Birmingham, UK. Paper 96GT27.

57 Bender W.R. Lean pre-mixed combustion, Gas turbine handbook, NETL, Pittsburgh, PA. https://www.netl.doe.gov/ sites/default/files/gas-turbine-handbook/3-2-1-2-pdf, 2019.

58 Klosinski J.P., Ekanayake S., Blanton J.C., Scipio A.I. Inlet bleed heat control system, US Patent No 20170167496A1, 2018.

59 Boyce M.P. (2002) Gas turbine engineering handbook, Chap. 7, Gulf Professional Publishing, Boston.

60 Roberts R., Eastbourn S.M. (2014) Modeling techniques for a computational efficient dynamic turbofan engine model, Int. J. Aerosp. Eng. 2014, 11, Article ID 283479, Hindawi Pub Corp.

61 Westfall C. (2015) Understanding compressor maps - sizing a turbocharger. https://www.dragzine.com/tech-stories/ power-adders/understanding-compressor-maps-sizing-a-turbocharger/.

62 Razak A.M.Y. (2007) Industrial gas turbines: Performance and operability, Woodhead Publishing Ltd, Cambridge, UK.

63 Schuhler T., Riche M., Orhon D., Zoughaib A., Busco A., Moliere M. (2018) Performances of gas turbines in O\&G applications: Simple thermodynamics methods help predict major trends, in: Proceedings of the ASME Turbine Technical Conference and Exposition 2018 Turbo Expo 2018, June 11-15, Lillestrom (Oslo), Norway. Paper GT2018-75046. 